\title{
Coronary artery bypass grafting and concomitant excision of chest wall chondrosarcoma Pankaj Kaul ${ }^{* 1}$, David JR Duthie ${ }^{1}$, Somsekhar Ganti ${ }^{1}$ and Radhika Ramnath ${ }^{2}$
}

Address: 'Yorkshire Heart Centre, Leeds General Infirmary, Great George Street, Leeds, LS1 3EX, UK and 2Department of Pathology, Saint James's University Hospital, Beckett Street, Leeds, LS9 7TF, UK

Email: Pankaj Kaul* - pankaj.kaul@leedsth.nhs.uk; David JR Duthie - david.duthie@leedsth.nhs.uk; Somsekhar Ganti - gantisom@hotmail.com; Radhika Ramnath - radhika.ramnath@leedsth.nhs.uk

* Corresponding author

Published: 18 February 2009

Journal of Cardiothoracic Surgery 2009, 4:7 doi:10.1186/1749-8090-4-7
Received: 14 October 2008

Accepted: 18 February 2009

This article is available from: http://www.cardiothoracicsurgery.org/content/4/1/7

(c) 2009 Kaul et al; licensee BioMed Central Ltd.

This is an Open Access article distributed under the terms of the Creative Commons Attribution License (http://creativecommons.org/licenses/by/2.0), which permits unrestricted use, distribution, and reproduction in any medium, provided the original work is properly cited.

\begin{abstract}
Coexistence of coronary artery disease and cancer with both requiring surgical treatment at the same time is rare. A 52 year male undergoing elective coronary artery bypass grafting was incidentally discovered to have a large soft tissue mass of variable consistency with cartilaginous elements arising from the right costal margin and adjoining ribs by a broad attachment and protruding into right pleural cavity. Frozen section suggested it to be either a chondrosarcoma or a teratoma. A wide excision of the mass with the adjoining muscle and periosteum along with quadruple coronary artery bypass grafting was done. This report is unusual on account of a) being the first reported case in world literature of concomitant excision of chondrosarcoma and coronary artery bypass grafting and $b$ ) the conservative management of the incidentally discovered chondrosarcoma by wide excision rather than chest wall resection with no local recurrence to date. Pathology of chondrosarcoma, in particular, and various management strategies when coronary artery disease and cancer coexist, in general, is discussed.
\end{abstract}

\section{Case presentation}

A 52 year old male smoker undergoing coronary artery bypass grafting for three vessel coronary artery disease and moderately impaired left ventricular function was felt to have a mass arising from the under surface of right costal margin adjacent to right lower sternal margin while sternopericardial ligament was being broken off by finger dissection prior to sternotomy. Preoperative chest X-ray suggested a soft, globular paracardiac shadow in relation to the right pericardiophrenic angle, appreciated better retrospectively (Figure 1) Sternotomy was made, the right pleura was opened to facilitate delineation of the mass. The mass measured $8 \times 6 \times 3 \mathrm{cms}$ and was arising from the right costal margin and the adjacent surfaces of $7^{\text {th }}, 8^{\text {th }}, 9^{\text {th }}$ and $10^{\text {th }}$ ribs (Figure 2). The mass was of firm to hard and variable consistency and was filled with cartilaginous material and there was no definite demarcation between the mass and the chest wall. The chest wall mass was excised in its entirety along with the intercostal muscle and the periosteum (Figure 3, Figure 4 and Figure 5). The frozen section revealed it to be either a chondrosarcoma or teratoma. Quadruple coronary artery bypass grafting to left anterior descending artery and its diagonal branch, obtuse marginal branch of circumflex artery and left ventricular branch of right coronary artery was performed using left internal mammary artery and long saphenous vein for conduits, employing cardiopulmonary bypass with antegrade cold blood cardioplegic arrest. Patient made uncomplicated postoperative recovery. 


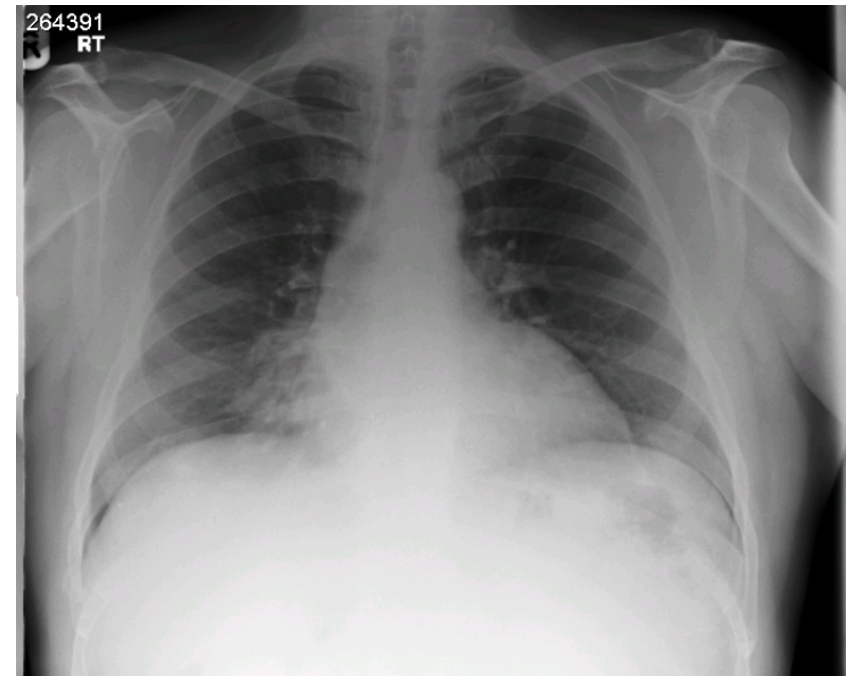

\section{Figure I}

Chest radiograph showing a soft lobular paracardiac shadow in right pericardiophrenic angle.

Histopathology revealed the overall appearances of grade 1 chondrosarcoma with a tumour composed of lobules of cartilage of varying size separated by fibrous tissue (Figure 6 ). The chondrocytes showed cytological atypia, binucleate cells, focal hypercellular areas with areas of calcification and necrosis (Figure 7). The tumour was seen to focally infiltrate into surrounding skeletal muscle.

The patient was discussed at the Regional Sarcoma MDT. Further excisional surgery in view of the positive surgical

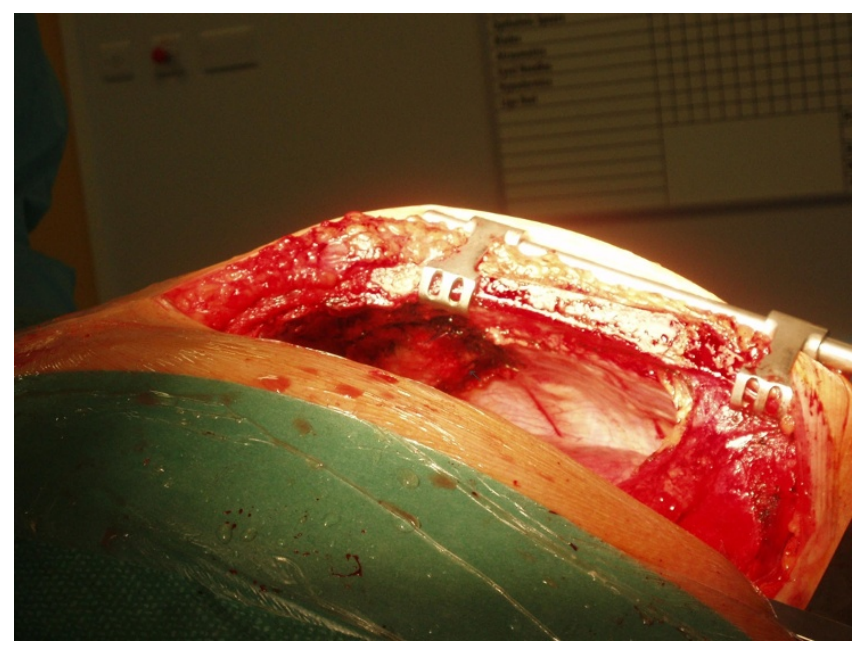

Figure 2

Intraoperative photograph showing large mass arising from inner surface of right costal margin and the adjacent ribs and protruding into right pleural cavity (arrow).

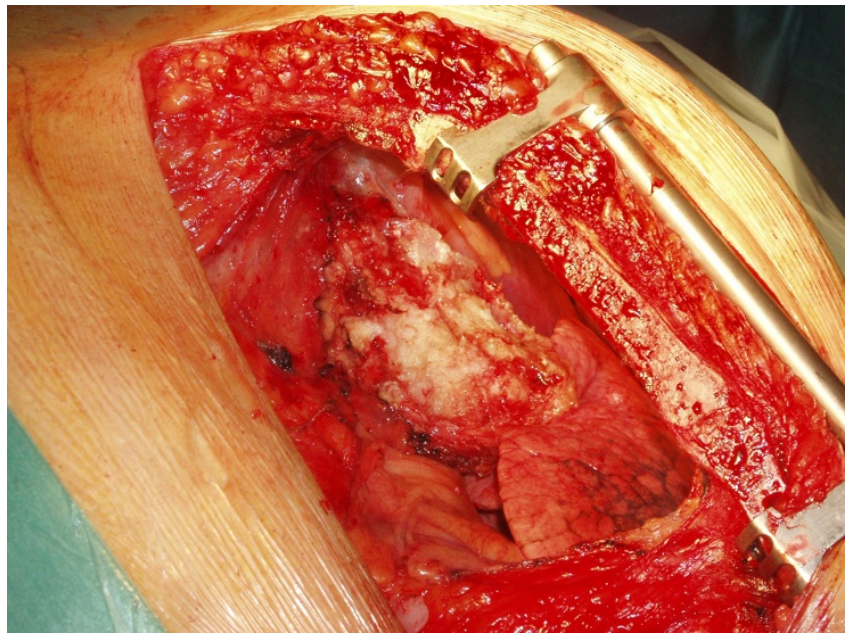

Figure 3

Intraoperative photograph showing the mass having been excised from the costal margin but still attached to the pleural remnants.

margins was not felt to reduce the risk of local recurrence in view of the possibility of microscopic seeding at surgery. There was also no role of adjuvant chemotherapy or radiotherapy in view of the known resistance of grade 1 chondrosarcoma.

Patient was discharged home on $7^{\text {th }}$ postoperative day. He has been followed at 3 monthly intervals with routine radiography including CT scans. He has made good recovery from the operation, is in NYHA class 1 and has shown

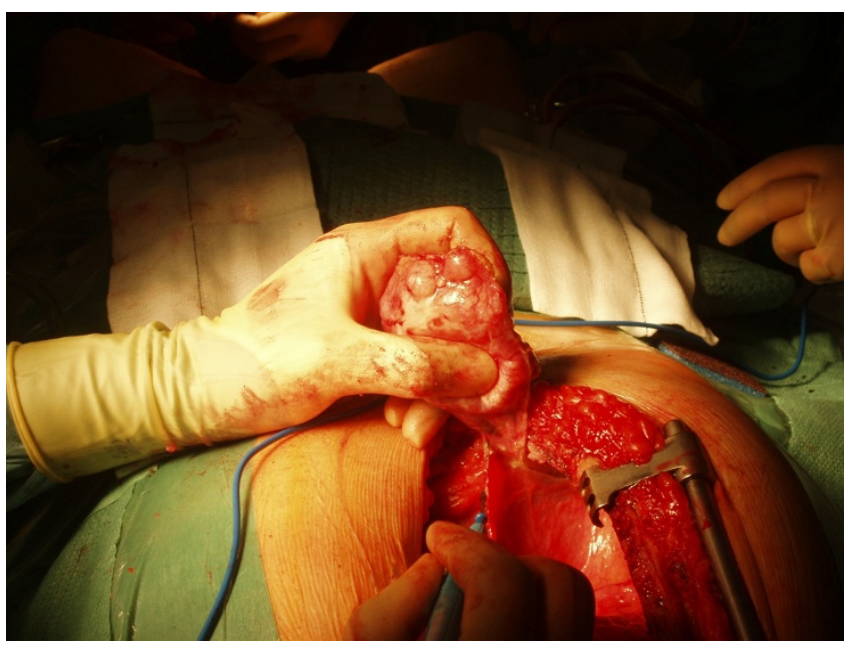

Figure 4

Intraoperative photograph showing the knobbly mass of uneven consistency being excised from last pleural remnants. 


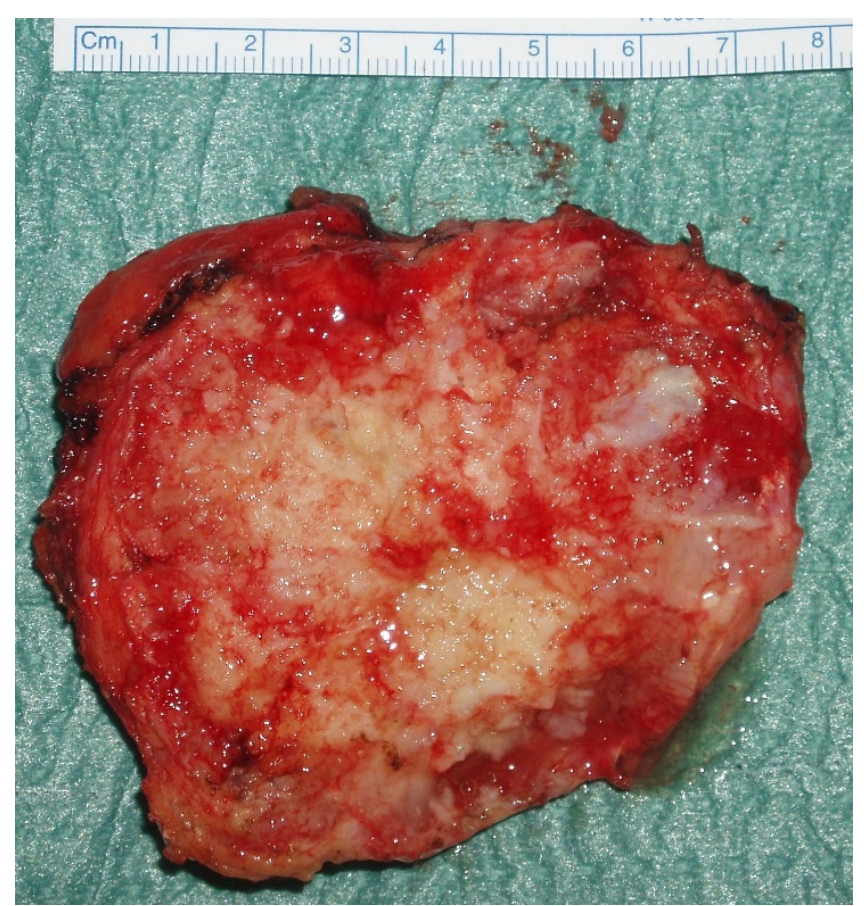

\section{Figure 5}

The excised tumour mass showing its irregular variegated costochondral surface interspersed with cystic and solid areas.

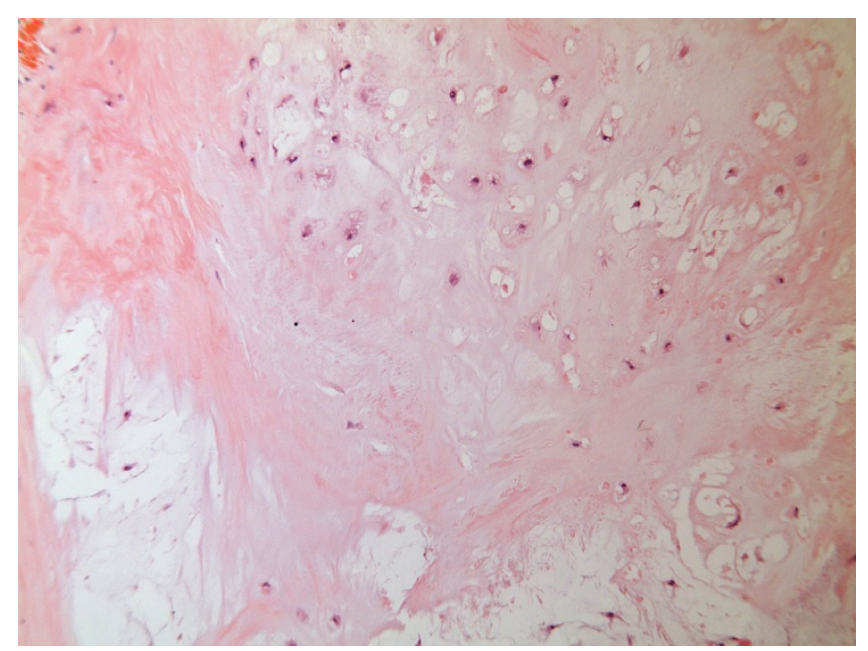

Figure 6

Histopathology picture (low power) showing grade I chondrosarcoma with lobules of cartilage separated by fibrous tissue.

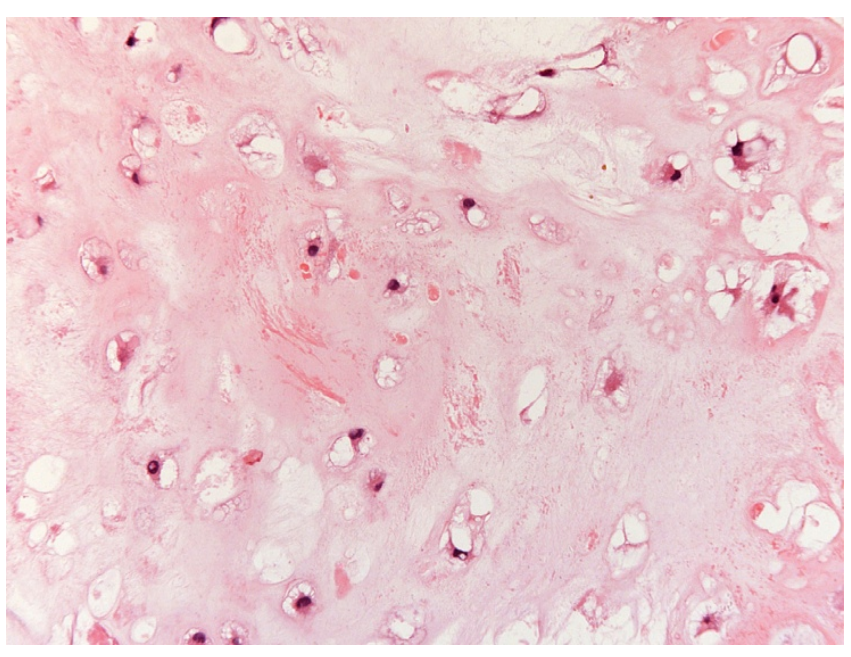

Figure 7

Histopathology picture (high power) showing lobules of cartilage composed of atypical chondrocytes.

no clinical or radiological signs of local recurrence, more than a year after his surgery.

\section{Discussion}

Chondrosarcoma accounts for nearly $30 \%$ of all malignant bone neoplasms and is the second most common matrix producing malignant tumour of bone. It is more common in central sites such as pelvis, proximal long bones and bones of anterior chest wall which, in turn, makes radical surgery difficult. $75 \%$ of chest wall chondrosarcomas arise from costochondral arches or sternum. The tumor most commonly occurs in the $3^{\text {rd }}$ to $5^{\text {th }}$ decades of life and is more frequent in men. Most chondrosarcomas arise de novo, but causal relationship between benign cartilaginous tumors [1], trauma [2,3], fibrous dysplasia and Paget's disease [4] has been described. Most patients present with a painful, slowly enlarging mass which appears radiologically as a lobulated mass in the medulla of the bone, with poorly defined margins, cortical thickening or destruction depending on the grade of the tumour, mottled, flocculent calcified matrix, endosteal scalloping and, uncommonly, pathological fractures. Morphologically, chondrosarcomas are subclassified into conventional intramedullary and juxtacortical, clear cell, dedifferentiated [5] and mesenchymal variants. Conventional chondrosarcomas have lobules of hyaline and myxoid cartilage in the medullary cavity, growing through the cortex and forming a well defined circumcised mass. Grade 1 chondrosarcomas have only mild hypercellularity, infrequent mitotic activity and sparse binucleate cells. Grade 3 chondrosarcomas, on the other hand, demonstrate marked hypercellularity, frequent mitoses, extreme pleomorphism and bizarre tumour giant cells, seen more predictably with chondroblastic osteosarcoma. The clear 
cell chondrosarcomas have osteoclast type giant cells with clear cytoplasm with reactive bone formation mimicking osteosarcomas. Mesenchymal chondrosarcomas comprise islands of hyaline cartilage surrounded by sheets of small round cells making differentiation from Ewing's sarcoma or even hemangiopericytoma occasionally difficult. Mesenchymal variant as also the clear cell subtype are typically seen in younger patients. The dedifferentiated chondrosarcomas have a dedifferentiated component similar to a malignant fibrous histiocytoma or a fibrosarcoma in terms of its anaplastic content and aggressive behaviour [6].

Our patient was a 52 year old male, with no antecedent history of trauma, with no symptoms suggestive of the presence of chest wall chondrosarcoma, even when seen retrospectively. The mass was arising from the right costal margin and the adjacent ribs, but mostly growing into the soft tissues inwards towards the pleural cavity. The gross appearances of the mass including its cartilaginous texture, and its variable density with intervening solid and cystic areas, suggested either a teratoma or a chondrosarcoma. It was considered inappropriate to proceed with just the coronary artery surgery as initially planned in the presence of a tumour which could be malignant. A wide excision was therefore performed with in continuity excision of the chest wall muscle and periosteum but without resection of the ribs in view of the number of ribs involved. Frozen section suggested either a possibly malignant cartilaginous tumour or a teratoma. Since frozen section also suggested the possibility of teratoma, further resection of all the ribs, with whose periosteum the tumor was in contiguity, was considered excessive both in light of the number of ribs involved as well as the possibility of microscopic seeding having already taken place even if paraffin sections would later confirm a chondrosarcoma. The paraffin section, 12 days later, confirmed grade 1 chondrosarcoma with positive margins.

In view of the central location of chondrosarcomas, wide excision, including that of the bones and cartilages from which they arise, is not always possible. However, a chest wall chondrosarcoma is ideally treated by wide excision including that of the rib from which it arises. Excision of as many as 4 ribs has been reported [7] and a variety of materials have been used including double prolene mesh [8], tantalum mesh [9], bovine pericardium [10] and Marlex mesh with metal plates [7]. Chondrosarcomas are resistant to both chemotherapy and radiotherapy [11], although mesenchymal chondrosarcomas have been treated with wide excision and chemotherapy [12].

Coexistence of malignancy in patients undergoing surgery for coronary artery disease or valvular disease requires careful risk benefit analysis of various options available.
Advanced, incurable malignancy associated with a limited prognosis may render surgical revascularisation inappropriate. A staged CABG procedure either before or after curative surgery for cancer is associated with advantages and disadvantages, determined in part by the organ involved by cancer and the urgency of the requirement for surgical revascularisation. In general, CABG before cancer surgery protects the patient from the risk of perioperative infarction during cancer surgery and confers a certain degree of haemodynamic stability during subsequent cancer surgery. It, however, delays the institution of potentially curative cancer surgery and subsequent chemotherapy or radiotherapy. It may also make cancer surgery technically more difficult if an intrathoracic cancer operation is needed. Simek et al, thus, reported carotid endarterectomy 2 months prior to aortic valve replacement and coronary artery bypass grafting followed 3 months later by successful meningioma excision in a 76 year old patient. [13]. Although concomitant surgery increases the duration of anaesthesia and surgery, and might result in higher bleeding complications owing to systemic heparinisation, it might quite often be the favoured option in view of the survival advantage of the earlier removal of a life threatening tumour.

Simultaneous planned excision of left atrial myxoma and CABG would seem obvious [[14] and [15]] but lung cancer has been frequently resected as a combined operation with CABG with no increase in either mortality or morbidity [16] including bilateral lung cancers though a median sternotomy [17]. Anatomic closeness of thymus lends it to concomitant excision along with coronary artery bypass grafting or other open heart procedures when affected by malignant disease. Ohshima et al reported combined CABG and excision of invasive thymoma [18], Kouzu et al reported CABG, aortic valve replacement and thymectomy for a mixed type thymoma [19] and Poullis et al described combined CABG and thymectomy for thymoma with pure red cell aplasia [20]. Successful off pump CABG has been described simultaneously with esophagectomy through left thoracoabdominal or transhiatal [21] approaches for oesophageal cancer, gastrectomy for gastric cancer [22] and Miles' operation for rectal cancer [23], with avoidance of heparinisation a distinct advantage in preventing bleeding complications. Both Litmathe et al [24] and Wolfhard et al [25] reported good results with simultaneous CABG and parathyroid resection for adenoma or simultaneous CABG and thyroidectomy whether for benign or malignant disease. Again, one stage surgical management of renal carcinoma complicated by inferior caval vein infiltration and coronary artery disease, with initial nephrectomy, excision of inferior vena caval and right atrial tumour under circulatory arrest followed by distal coronary anastomoses during rewarming have been successfully reported $[26,27]$. 
Presence of a concomitant phaeochromocytoma in a patient with coronary artery disease requires careful preoperative and intraoperative management of both pathologies in terms of blood pressure control, myocardial protection and haemostasis. To et al reported the first successful cases of combined coronary artery bypass grafting and laparoscopic adrenalectomy for phaeochromocytoma and excision of extra adrenal phaeochromocytoma [28]. Subsequent successes were described by Garg et al [29] and Balabaud-Pichon et al [30]. Chkuaseli et al described simultaneous successful coronary artery bypass grafting and panhysterectomy for endometrial carcinoma [31]. Similarly, successful concomitant coronary artery surgery has been described with curative excision of both male [32] and female [33] breast carcinoma. Chest wall tumours rarely coexist with coronary artery disease. Kostolny et al described extended resection of a chest wall desmoid tumour which had infiltrated inwards to involve a previous left internal mammary graft to left anterior descending coronary artery. The chest wall tumour along with LIMA was excised in continuity, a saphenous vein bypass graft fashioned off pump and chest reconstructed with polypropylene mesh and a latissimus dorsi musculocutaneous flap [34]. Rozhledy et al reported actinotherapy and hyperthermia followed by coronary artery bypass grafting, sternal resection and latissimus dorsi myocutaneous transposition in a patient with metastatic non differentiated carcinoma of sternum in whom the primary tumour was found neither preoperatively nor during a 36 month postoperative remission [35].

All the above, however, describe concomitant coronary artery surgery with excision of carcinomas affecting various organs of the body when the diagnosis of malignancy was made preoperatively. When malignancy is detected incidentally, for the first time, during a coronary artery bypass operation, or, indeed, any open heart operation, a quick, on the spot evaluation of the various management options and their risk benefit potential is required. Fortunately such a discovery is extremely rare during open heart surgery. Mirsadraee et al described the successful excision of a locally infiltrating asymptomatic incidentally discovered malignant thymoma along with coronary artery bypass grafting [36]. Abdullah et al described excision of a previously unsuspected thymic carcinoid during urgent CABG [37]. Guo et al cautioned that all enlarged internal thoracic lymph nodes during internal thoracic artery mobilisation should be sent for histopathology and reported three such incidental discoveries during LIMA mobilisation for CABG, two of the patients having previously undiagnosed lymphomas and the third a metastatic carcinoma of breast [38]. Walker et al suspected phaeochromocytoma in a patient undergoing coronary artery bypass grafting by extreme episodic spontaneous hypertensive episodes resulting in tearing of anastomoses, sub- sequently confirmed by laboratory findings and diagnostic imaging [39].

To conclude, chondrosarcoma of the chest wall may rarely coexist in a patient with coronary artery disease that requires surgical revascularisation. If the diagnosis of chondrosarcoma is made before CABG, the management, ideally, consists of excision of the tumour with a wide clearance including the ribs from which it arises, with reconstruction of chest wall with various synthetic meshes available. This could be done before, during or after coronary artery surgery depending on the urgency of revascularisation. If, however, the tumour is discovered incidentally during coronary surgery, the frozen section is not unequivocal and the tumour arises from a wide base necessitating an elaborate chest wall reconstruction, a wide resection, without excision of multiple ribs necessarily, and CABG, followed by careful surveillance for local recurrence is not inappropriate.

\section{Consent}

Written informed consent was obtained from the patient for publication of this case report and accompanying images. A copy of the written consent is available for review by Editor-in-Chief of this journal.

\section{Competing interests}

The authors declare that they have no competing interests.

\section{Authors' contributions}

PK conceived, designed and drafted the manuscript and was the principal operating surgeon and consultant in charge of patient's care. DD was the anaesthetic consultant responsible for patient's anaesthetic and ICU care and made valuable suggestions. RR made the histopathological diagnosis and supplied the histopathology pictures. GS critically evaluated the manuscript and contributed intellectually.

\section{References}

I. Pairolero PC: Chest wall tumours. In General Thoracic Surgery 4th edition. Edited by: Shields TW. PA: Williams and Wilkins; 1994:583.

2. Lichtenstein L: Bone Tumours. 5th edition. St Louis: CV Mosby; 1977:186

3. McAfee MK: Chondrosarcoma of the chest wall: factors affecting survival. Ann Thorac surg 1985, 40:535.

4. Ron IG, Amir G, Inbar MJ, Chaitchik S: Clear cell chondrosarcoma of rib following repetitive low impact trauma. Am J Clin Oncol 1995, 1 8:87-9.

5. Rosenberg AE: Skeletal system and soft tissue tumours. In Robbins Pathologic Basis of Disease 5th edition. Edited by: Cotran RS, Robbins SL, Kumar V. Philadelphia, Pennsylvania: WB Saunders Company; I994: I 240.

6. Ishida T, Kuwada Y, Motoi N, Oka T, Machinami R: Dedifferentiated chondrosarcoma of the rib with a malignant mesenchymatous component: an autopsy case report. Pathol Int 1997, 6:397-403.

7. Shimoyama T, Suzuki R, Yoshiya K, Yamato Y, Koike T: Chondrosarcoma of the rib. Jpn J Thorac Cardiovasc Surg 2003, 5 I: I67-7I.

8. Fukuzumi M, Kadokura M, Murata N, Yamamoto N: Chondrosarcoma of rib origin: report of a case. Kyobu Geka 2006, 59:50 I-4. 
9. Hull DA: Massive chondrosarcoma of the rib with extension into colon: repair with tantalum mesh. Ann Surg 1954, |40:886-91.

10. Chang LY, Lee MC, Chang CH: Chondrosarcoma of the rib - a case report. Changgeng Yi Xue Za Zhi 1989, I 2:107-10.

II. Ben MRS, el Hammami S, Merai S: Costal chondrosarcoma. 4 cases. Presse Med 1999, 28:1355-60.

12. Aoki T, Watanbe M, Takagi K, Tanaka S, Aida S: Mesenchymal chondrosarcoma of the rib: report of a case. Surg Today 1996, 26: $1020-3$

13. Simek M, Vaverka M, Nemec P, Krahulik D, Palka J, Plesnikova Y: Combined approach to the treatment of severe aortic stenosis and to three vessel disease in patients with brain meningioma and severe stenosis of internal carotid artery. Cas Lek Cesk 2005, I 44(I I):756-758.

14. Gismondi RA, Kaufman R, Correa GA, da Cunha AB: Left atrial myxoma associated with obstructive coronary disease. Arq BrasCardiol 2007, 88(I):el-e3.

15. Koike N, Kaneko T, Ezure M, Sato Y, Aizaki M, Okada S, Morishita Y: Left atrial myxoma combined with coronary artery bypass grafting. Kyobu Geka 2006, 59( I 2): 1089-1094.

16. Vojacek J, Hluboky J, Burkert J, Brazdil J, Lischke R: Simultaneous cardiac and thoracic operations. Zentr Chir 2006, | 3 I (3):200-205.

17. Kanzaki M, Kanno M, Onuki T: Combined bilateral lung resections and off pump coronary artery bypass grafting. Ann Thorac Cardiovasc Surg 2002, 8(6):393-395.

18. Ohshima K, Ishikawa S, Yoshida I, Ohtaki A, Ohtani Y, Morishita Y: A concomitant operation of coronary artery bypass grafting and thymectomy: a case report. Kyobou Geka 1994, 47( I 2): 1029-103I.

19. Kouzu S, Fujii N, Shinohara M, Sode Y, Yoshioka J, Akahane K, Tozuka $\mathrm{N}$, Sawaki S: A case of angina pectoris and aortic regurgitation combined with thymoma. Kyobu Geka 1993, 46:359-62.

20. Poullis M, Punjabi P: Concomitant thymectomy and cardiac operation in a patient with pure red cell aplasia. Ann Thorac Surg 200I, 72:62I-3.

21. Jones JM, Melua AA, Anikin V, Campalini G: Simultaneous transhiatal esophagectomy and coronary artery bypass grafting without cardiopulmonary bypass. Diseases of the Esophagus 1999, I 2:312-3.

22. Suzuki K, Miyamoto M, Ikeda N, Shigeta K, Kouchi $Y$, Miyashita $H$ : Simultaneous surgery for unstable angina and gastric cancer: a case report. Kyobu Geka 200I, 54:305-9.

23. Mikata S, Kuki S, Matsumura R, Okuda A, Yoshikawa K, Ito A: A successful case of concomitant operation for coronary artery disease and rectal cancer in elderly patient. Nippon Kyobu Geka Gakkai Zasshi 1991, 39(I2):2187-2190.

24. Litmathe J, Kurt M, Boeken U, Roehrborn A, Feindt P, Gams E: Combined cardiothoracic surgery and interventions of the parathyroid gland. A rare clinical coperation. Zeitschrift fur Kardiologie 2005, 94:28-32.

25. Wolfhard U, Krause U, Walz MK, Lederbogen S: Combined interventions in heart and thyroid surgery - an example of interdisciplinary cooperation. Chirurg 1994, 65( I 2): I 107-IIII0.

26. Franke UF, Wahlers T, Wittwer T, Schubert J: Renal carcinoma with caval vein infiltration and triple coronary disease: one stage surgical management. Eur J Card Surg 2001, 20:877-9.

27. Akchurin RS, Davidov MI, Partigulov SA, Brand JB, Shirlaev AA, Lepilin MG, Dolgov IM: Cardiopulmonary bypass and cell-saver technique in combined oncologic and cardiovascular surgery. Artificial Organs 1997, 2 1:763-5.

28. To AC, Frost C, Grey AB, Croxson MS, Cooper J: Combined coronary artery bypass grafting and phaeochromocytoma excision. Anaesthesia 2007, 62:728-33.

29. Garg A, Banitt PF: Pheochromocytoma and myocardial infarction. Southern Medical Journal 2004, 97:98I-4.

30. Balabaud-Pichon V, Bopp P, Levy F, Thiranos JC, Steib A: Excision of adrenal pheochromocytoma and coronary artery bypass graft surgery with cardiopulmonary bypass. Journal of Cardiothoracic and Vascular Anaesthesia 2002, 16:344-6.

31. Chkuaseli GT, Lominadze SE, Katsitadze ZD, Dzhangavadze MS, Grigoliia GN: Case of simultaneous operations of aortocoronary shunt and panhysterectomy. Georgian Medical News 2006, 135:16-18.
32. Aydin $\mathrm{H}$, Gokbayir $\mathrm{H}$, Tezcaner $\mathrm{T}$, Zorlutuna $\mathrm{Y}$ : Combined surgery for ischaemic heart disease and breast cancer in male: a case report. Anadolu Kardiyoloji Dergisi 2006, 6:83-4.

33. Anisimowicz L, Jarmoszewicz K, Kruszewski J, Jagielak D, Kopacz A, Narkiewicz M: Simultaneous coronary artery bypass grafting on the beating heart without assisted circulation and radical modified Patey mastectomy. Wiadomosci Lekarskie 2000, 53:693-6.

34. Kostolny M Jr, Prauer H, Augustin N, Lange R: Extended resection of a chest wall desmoid tumour with concomitant coronary artery bypass grafting. Eur J Cardiothor Surg 200I, 20:1040-I.

35. Hlubocky J, Vojacek J, Fera J, Pafko P, Lischke R, Kubala E, Spatenka J, Burkert J: Resection of metastatic nondifferentiated carcinoma of sternum with thoracic wall reconstruction and simultaneous myocardial revascularisation for ischaemic heart disease - case report. Rozhl Chir 2006, 85(5):216-219.

36. Mirsadraee S, Shah SS, Kumar B, Kaul P: Incidental locally infiltrating malignant thymoma and coronary artery bypass surgery - excision should always be considered. Journal of Cardiac Surgery 2005, 20:291-2.

37. Abdullah F, Loon G: An incidental finding of thymic carcinoid during urgent CABG operation. Heart Surg Forum 2002, 5(4):E305-E306.

38. Guo LR, Myers ML, Kirk ME: Incidental malignancy in internal thoracic artery lymph nodes. Annals of Thoracic Surgery 200I, 72:625-7.

39. Walker T, Bail DH, Schmid E, Haeberle L, Kuehne H, Ziemer G: Challenging the advanced: cardiac surgery without awareness of a pheochromocytoma. Thoracic and Cardiovascular Surgeon 2006, 54:498-9.
Publish with Bio Med Central and every scientist can read your work free of charge

"BioMed Central will be the most significant development for disseminating the results of biomedical research in our lifetime."

Sir Paul Nurse, Cancer Research UK

Your research papers will be:

- available free of charge to the entire biomedical community

- peer reviewed and published immediately upon acceptance

- cited in PubMed and archived on PubMed Central

- yours - you keep the copyright

Submit your manuscript here:

http://www.biomedcentral.com/info/publishing_adv.asp
BioMedcentral 